\title{
The Manifestation of Code Switching Among 3 Year-Old Yoruba/English Semilinguals
}

\author{
Akinkurolere Susan Olajoke (Corresponding author) \\ ${ }^{1}$ Department of General Studies, Rufus Giwa Polytechnic, Owo, Ondo State Nigeria \\ ${ }^{2}$ Department of English, Obafemi Awolowo University, Ile-Ife Osun State, Nigeria
}

Tel: 234-803-209-9737Ｅ-mail: olujoke2126@yahoo.com

\begin{abstract}
Abuya, Eromosele John
Department of General Studies, Rufus Giwa Polytechnic, Owo, Ondo State Nigeria

Tel: 234-813-123-1331Ｅ-mail: abuyaej@yahoo.com
\end{abstract}

Received: January 19, 2013 Accepted: March 2, 2013 Published: March 2, 2013

doi:10.5296/ijele.v1i1.3340 URL: http://dx.doi.org/10.5296/ijele.v1i1.3340

\begin{abstract}
Communication is the most symbolic function of language. Hence, The present study explored the manifestation of code switching with reference to ten selected 3 year- old school children .Code switching as a sociolinguistic phenomenon has been studied by various scholars but efforts have not been made to assess its manifestation among school children in the context of Yoruba/English. The Yoruba language serves as the children first language and the English language serves as the second language (L2). The children at this acquisition age code-switch for diverse reasons and these showed that the manifestation of code switching at this age is distinct from that of adult since the children are at the language acquisition stage. With a critical focus, the paper presents appealing case studies and analysis that are useful in gaining deeper insights into reasons that make code switching as a linguistic phenomenon an unavoidable ornament in the beautification process of language learning of children known as language acquisition.
\end{abstract}

Keywords: communication, language, semilingualism, codeswitching, acquisition, bilingualism, codemixing, mother tongue 


\section{Introduction}

At every stage of human life, communicating with others is imperative. The fetus in the womb has a way of communicating with its mother distinctively unique ways, especially when the baby is mature for delivery. Language is the primary means of communicating and it is an arbitrary vocal system of communication used among members of a speech community (Dada 2004). The concept of code switching among bilingual children is no longer a mirage but a reality that we have to welcome. The children at the age are passionately quest for self expression at every opportunity.

Bokamba (1989) in Ayeomoni (2006:91) defines code switching as the mixing of words, phrases and sentences from two distinct (sub) system across sentence boundaries with the same speech event.... All over the world, the language use of diverse communities especially where languages are in contact demonstrates code switching. The status of English language as the official language and thus, serves as the language of education can never be overemphasized as the major factor for code switching among children. Owusu-Ansah and Torto (2013:69) opine that:

The use of English as the teaching medium within the educational system tends to be preferred to the use of an indigenous language. Some parents are disappointed when they learn that their children are learning their own languages at school. Such parents do not understand why they should pay fees only for their children to learn languages they already speak (Andoh-Kumi, 1997). For most parents in Ghana, the purpose of schooling is to learn and be proficient in the English language. Competence in English is a means to one's well-being and prosperity. English therefore consolidates its position as the only language suitable for use in the local educational system.

Also, Ayeomoni (2012) aptly describes language contact, co-existence of both foreign and indigenous languages in multilingual environment as factors responsible for borrowing, interference, code-switching, code-mixing, and domestication or nativisation of foreign languages. The phenomenon of code switching has become highly embedded in such global communities, Nigeria not exclusive, to an extent that it has become an area of research interest to scholars in the field of communication, and linguistics. This makes code switching a product of bi/multilingualism.

The concept of code mixing is closely associated with code switching. Bamiro (2006:23) makes a distinction between code-mixing and code-switching from Bray Kachru's submission thus;

Code-switching entails the ability to switch from code A to code B. The alternation of code is determined by the function, the situation, and the participants. In other words, it refers to categorization of one's verbal repertoire in terms of functions and roles ....code-mixing, on the other hand, entails transferring linguistic units from one code into another. Such a transfer (mixing) results in developing a new restricted or not so restricted code of linguistic interaction. One may consider code switching as a process which can result in code mixed varieties. A multilingual or multidialectal person is generally able to associate a function and 
an effect with various types of language or dialect mixes (kachru 1978;108-9).

Hence, any natural discourse that involves the use of or more languages could either be code switching or code mixing.

Di Petro (1977:3) defines code switching as the use of more than one language by communicants in the execution of a speech act just as Fallis (1976:877) defines code switching as 'the alteration of two languages'. To Scotton and Ury (1977:5), Code switching refers to the use of two or more linguistic varieties in the same conversation or interaction'.

Drawing a clear cut distinction between code switching and code mixing is not easy especially in literary contexts but Bakamba (1989) definition of code mixing as 'the embedding of various linguistic units such as affixes (bond morphemes), words (unbounded morphemes), phrases and clauses from a co-operative activity where the participants in order to infer what is intended must reconcile what they hear with what they understand', presents code mixing as a distinct linguistic phenomenon from code-switching based on the fact that it operates at lower units when compared to code-switching.

Code-switching has been studied from various perspective ranging from sociology, psychology, to anthropology. The present paper approaches the phenomenon of code switching from the perspective of socio-cultural linguistics. In the interpretation of a code, the culture of the language(es) is taken into consideration, hence when languages come into contact, the cultures are also in contact, the resultant effect could make meaning complex most times. This could be referred to as culture- shifting or culture- mixing.

Children at pre-school or play group age learn pragmatic lessons about language and communication and make meaningful utterances. The children are still in the process of acquisition. More so, with exposure to more than one language at such acquisition period, they explore the opportunities open to them and maximise communication through code switching or code mixing. The children at this stage are natural semilinguals, even though, they might still grow up to overcome this phenomenon in their teens and adult lives.

Semilingualism is a concept that denotes lack of mastery in the two or more languages by an individual or a group of people, this term could also be used to refer to underdevelopment in the acquisition of more than two languages especially by children. This phenomenon manifests in the utterances of such children. In general term, the children might be referred to as bilingual children but at the level of proficiency, they are semiliguals since they are yet to exhibit mastery of any of the languages being acquired.

At the acquisition stage, code-switching among the children could either be intended or unintended. We submit that intended code-switching takes place when the children actually meant to use different languages in a linguistic context while unintended code-switching occurs when the children make use of two or more languages in a linguistic context unconsciously.

There are certain misconceptions or ill founded assumptions about exposing children to two or more languages at early stage such as; 'bilingual children are likely going to get the 
languages mixed up confused or get confused' but the fact remains that the mix up crops up at the acquisition stage and the children later gain mastery of each language. This mix up is an evidence of learning and it provides researchers with the opportunity to avail themselves with diverse analysis.

Children at the age of 3 are at the optimal age whereby they can easily acquire any language since their minds are open and still flexible. Hence, this paper focuses on the 3 year old children that have Yoruba language as their mother tongue or first language, and also acquiring English language simultaneously.

\subsection{Research Objectives}

The research paper was meant to meet the following objectives:

i) observe the use of codeswitching among the selected children,

ii) identify the pattern of codeswitching that manifest in the children's utterances,

iii) analyse the pattern of codeswitching though Insight theory.

\subsection{Research Questions}

The motive behind this research was to delve on the manifestation of codeswitching among three year old children. To this end, the following research questions were specifically investigated in this study:

i) Does codeswitching have positive effect on the language acquisition of children?

ii) Why do children codeswitching?

iii) Is there any difference between codeswitching among children and adults?

\subsection{Theoretical Perspective}

This study will be analysed from the approach of sociolinguistics. Sociolinguistics approaches meaning in Linguistics in relation to social context that is, the society. The analysis of the manifestation of code-switching through the sociolinguistic approach will enable interpretation based on socio-cultural context of Yoruba/English. The linguistic theory for the analysis is based on Peng (1986) theory of Insight.

According to Peng (1986: 98) Insight means the attempt to achieve explanation or interpretation of what the text is about when it is measured against or placed in the 'context of situation' as a background. Insight theory will serve as the tool for the analysis of the data.

The participants for this study were 3year-old children that were observed in a play group within one week period. The children live on the same street and are at the acquisition stage of Yoruba and English languages. The researchers made frantic effort to familiarize with them by engaging them in communication so that they would be relaxed to communication freely in their presence. The children are made up of those that attend Public and Private kindergarten Schools in an urban city of Akure, Ondo State, Nigeria. Hence, they mostly attempt to communicate in English language. 


\section{Research Methodology}

The method for data collection was specifically through direct observation. The children were watched and interrogated as they communicate in a play group within a time range of two weeks. Hence, the data for discussion and analysis were from the natural discourse of the 3 year old semilinguals. Ten significant instances of code-switching among the children were selected randomly for the purpose of our analysis. The instances are labelled I -- X. The data were translated and analyzed according to Insight theory of Peng (1986).

\section{Data Presentation and Analysis}

As earlier stated, the analysis will be done through the application of insight theory to the selected data for the revelation of social and cultural structure of code-switching in relation to semiligual children. The translation in English language follows the data that are italiclised.

I) I want to drink water jo (I want to drink water, please).

Insight: One of the children became thirsty in the process of playing with his peers and rather than taking permission, he just announced his need. This code-alternation is an example of code switching whereby, the child brought in a word from Yoruba language. The culture of Yoruba is brought to bear on the utterance through the use of 'please'. Also we could say that the 'please' that ended the statement was meant to demonstrate emphasis or desperation to leave his play group at that particular point. The expression is an indirect way of taking his leave. The code switching in this sentence might be unintended.

II) Give me Akara (Give me Beanscake)

Insight: 'Akara' (beanscake) is a type of food that is common to Yoruba people .The child at this acquisition stage has not registered the English word for 'Akara' in her memory. It could also be that she had forgotten. Hence, she needed to import a word from Yoruba language to express herself in the situation, the code-switching is an example that is intended.

III) O ti to, stop it (it is alright, stop it)

Insight: The switch to the English language from the child is to stress what he had said in the vernacular, in the course of playing in a group, the child wanted the others to stop filling the can with sand believing it was full enough for him to carry on his head. Hence, after saying ' $\mathrm{O}$ ti to' (it is alright), he went ahead to say 'stop it'. This was purposively done by the child to pass across his message to his peer in strong terms. Therefore, the child employs an imperative sentence from the English language for effective communication.

IV) a) Speaker A: What is your name?

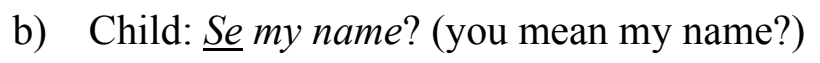


Insight: The child's response to the question through the introduction of vernacular code was merely for confirmation. This is a common characteristic among little children since they quest for assurance coupled with certainty at every available opportunity . The child understood the question but only needed reassurance before answering, in the process of doing this, he brought into the sentence a indigenous code. He achieved his intention through emphasy. It is crystal clear, that the response by the child is not a reply an indirect interrogative sentence in a statement format. The statement is an example of intended code switching.

V) a) Speaker A: What did you eat for breakfast?

b) Child: Beans and Dodo (Beans and fried plantain)

Insight: The child code-switched by making use of the word 'Dodo'. It is possible that the child did not know the right word for it in English language. Children are generally familiar with the foods they eat especially their favourites. It is what they hear their mothers or caregivers call the food that they call it .In this case, the child might not be conscious of the fact that he had code-switched by the use of the word 'Dodo'. Since the primary language of the conversation is English. An instance like this is most likely to be unintended code switching.

VI) a) Speaker A: Where is your shoe?

b) Child: see, wo! (see, see!)

Insight: The code-switching that occurs in the above utterance demonstrates an attempt by the child to lay emphasis on his response through repetition, when he discovered that the other participant was not getting his message on time, he code-switched. This attempt is intended by the child to make the first speaker understand him better.

VII) a) Speaker A: Wear your trouser.

b) Child: Sebi is sokoto (I think it is trouser)

Insight: The above evidence of code-switching shows that the child has mastered the word 'trouser' and its translation in Yoruba language. The discourse between the child and the participant shows that the child only wanted to ascertain what he already knew. By this he demonstrated his prowess in both English and Yoruba languages.

VIII) a) Speaker A: Come and have your bath.

b) Child: kokoro is inside the water (Insect is inside the water)

a) Speaker A: Remove the insect

b) Child: No

Insight: At times, certain words and probably the sounds of such words appeal to the hearing of the children in one language than the other. The child in the above utterance knew that insect is the word for 'kokoro' in Yoruba language, yet he went ahead to 
code-switch .Probably, just for the fun of it, since there is no assumption that shows that children prefer certain words in one language than the other the child is believed to have code-switched intentionally.

IX) Child: Yinka sori (Yinka sorry)

Insight: The code-switching that manifests at this level is covert or indirect code switching (see Bamiro 2006:30), this brings about the mark of identity since the child pronounced 'sorry' with an intonation of Yoruba language. Cases that relate to indirect code switching are common among children. The child only tried to express his concern and sympathy for another child that fell down in the course of play session but as a Yoruba /English Semilingual, he unconsciously brought the intonation of Yoruba language to bear on the English language word 'sorry'.

In comparison to Bamiro (2006) which bothers on the use of codeswitching in literary work, it is observed that the linguistic phenomenon of codeswitching manifests various instances of language use and this cuts across age, sex, race e.t.c. Interestingly, this research paper is distinct in the sense that, the scope is restricted to children in the process of language acquisition, thus, the manifestation and reasons for such are distinct among children. In a nutshell, work of Bamiro (2006) is on the manifestation of codeswicthing among adults in a literary context. On the other hand, Ayeomoni (2006) concentrates on the style of languages employed in childhood, in his work, questionnaires were administered to adult in order to elicit data for analysis.

\section{Conclusion}

From our analysis, we are able to discover the fact that although semilingual children in Yoruba /English acquire both languages, there is dominance of English language at the expense of Yoruba language, especially in the educational setting. No wonder, Owusu-Ansah and Torto (2013:68) submit thus:

However, it is worth noting that attitudes towards the use of the indigenous languages within the educational sector remain rather argumentative. Teachers of indigenous languages are not much sought after and, quite often, students do not consider them as proficient academically as teachers of other subjects (Bamgbose, 1991)

In fact, they further argue that:

Today, in some public Kindergarten Schools in Ghana, both the local languages and English are employed in communication but the latter has a higher percentage of usage. On the other hand, in private schools of the same level, only English is used in interaction. At urban areas, many pupils in Kindergarten can speak English since their parents speak English with them at home. Teaching children at that early stage of education in English is facilitated by the choice of English over the local language by parents.... Teachers communicate in English with their pupils and encourage them to speak English always.

It therefore falls within our expectation that, despite the fact that, the data for our analysis were randomly selected from informal setting yet, the primary language of discussion among 
the children that have been exposed to kindergarten training is English language. Based on our analysis, we are able to make a distinction between intended and unintended code switching among 3 year old semilingual children.

Among the children, code-switching functions from asserting meaning, laying emphasy, promoting interpersonal relationship, to seeking approval. The sociolinguistic situation described in this study depicts the fact that local languages are in a substractive polyglossic relationship with English language. As Bamiro (2006: 33) submits thus:

Subtractive polyglossic is my term for the dominance and a secondary of the English language at the expense and decline of the local languages...Consequently, English functions in more domains and carries more 'vehicular load' to use Quirk et al's term (1972:2), than Nigeria's local languages.

The manifestation of code-switching among children is different from that of Adult, since instances of code-switching that result from emphasy and repetition are not common among adult. The manifestation of code-switching at this level portrays the children as semilinguals, that is, it shows clearly that they have not fully acquired or gain mastery of the two languages. Despite this, their discourse serves as evidence that they are learning and at times, instances of code-switching can be used to measure their stage or level of language acquisition. Thus, making code-switching an unavoidable ornament in the beautification process of languages acquisition.

We wish to recommend a speech act analysis of children utterances for the purpose of bringing to fore the directness and indirectness of linguistic acts in their speeches, this will lend an interesting voice to academic debate that bothers on speech acts and children speeches.

\section{References}

Ayeomoni M. O. (2006). Code switching and code-mixing: Style of language use in childhood in Yoruba speech community. Nordic Journal of African Studies, 15(1), 99.

Ayeomoni M. O. (2012). The languages in Nigeria socio-political domains: Features and functions. English Language Teaching, 5(10), 12-19. Canadian Center of Science and Education.

Bokamba E. (1989). Are there syntactic constraints on code-mixing? World Englishes, 8(3). http://dx.doi.org/10.1111/j.1467-971X.1989.tb00669.x

Bamiro E. O. (2006). The politics of code switching: English vs Nigerian languages. World Englishes, 25(1) 23-35. http://dx.doi.org/10.1111/j.0083-2919.2006.00445.x

Dada S. A. (2004). The principles of effective public speaking (p. 2) Ibadan: Emman Publications.

Di Pietro R. J. (1977). Code switching as a verbal strategy among bilinguals. In Robert F. Eckman (eds), Current Themes in Linguistics: Bilingualism, Experimental Linguistics, and Language Typologies (p. 3). Washington, DC: Hemisphere. 


\section{Macrothink \\ International Journal of English Language Education \\ ISSN 2325-0887 2013, Vol. 1, No. 1}

Fallis, G. V. (1978). Code switching in bilingual Chicano Poetry. Hispania, 59, 877. http://dx.doi.org/10.2307/340213

Kachru B. B. (1978). Code switching as a communicative strategy in India. In James E. Alatis (eds), Georgetown University Round Table on Languages and Linguistics: International Dimensions of Bilingual Education (pp. 108-109). Washington DC: Georgetown University Press.

Owusu-Ansah L. K., \& Richard T. Torto. (2013). Communication of language attitudes: An exploration of the Ghanaian situation. The International Journal of Language Learning and Applied Linguistics World (IJLLALW), 2(1), 68-69.

Peng F. C. (1986). On the context of situation. International Journal of Sociology of Language, 58, 98. http://dx.doi.org/10.1515/ijsl.1986.58.91

Scotton, M., \& Ury W. (1977). Bilingual strategies: The social functions of code switching. Linguistics, 193, 5.

\section{Copyright Disclaimer}

Copyright reserved by the author(s).

This article is an open-access article distributed under the terms and conditions of the Creative Commons Attribution license (http://creativecommons.org/licenses/by/3.0/). 